University of Nebraska - Lincoln

DigitalCommons@University of Nebraska - Lincoln

USDA National Wildlife Research Center - Staff Publications
U.S. Department of Agriculture: Animal and Plant Health Inspection Service

January 2008

\title{
Avoidance of hydrolyzed casein by mice
}

Kristin L. Field

Monell Chemical Senses Center, Philadelphia, PA

Bruce A. Kimball

Monell Chemical Senses Center, Philadelphia, PA, bruce.kimball@ars.usda.gov

Julie A. Mennella

Monell Chemical Senses Center, Philadelphia, PA

Gary K. Beauchamp

Monell Chemical Senses Center, Philadelphia, PA

Alexander A. Bachmanov

Monell Chemical Senses Center, Philadelphia, PA

Follow this and additional works at: https://digitalcommons.unl.edu/icwdm_usdanwrc

Part of the Environmental Sciences Commons

Field, Kristin L.; Kimball, Bruce A.; Mennella, Julie A.; Beauchamp, Gary K.; and Bachmanov, Alexander A., "Avoidance of hydrolyzed casein by mice" (2008). USDA National Wildlife Research Center - Staff Publications. 782.

https://digitalcommons.unl.edu/icwdm_usdanwrc/782

This Article is brought to you for free and open access by the U.S. Department of Agriculture: Animal and Plant Health Inspection Service at DigitalCommons@University of Nebraska - Lincoln. It has been accepted for inclusion in USDA National Wildlife Research Center - Staff Publications by an authorized administrator of DigitalCommons@University of Nebraska - Lincoln. 


\title{
Avoidance of hydrolyzed casein by mice
}

\author{
Kristin L. Field $^{\mathrm{a}, *}$, Bruce A. Kimball ${ }^{\mathrm{a}, \mathrm{b}}$, Julie A. Mennella ${ }^{\mathrm{a}}$, \\ Gary K. Beauchamp ${ }^{\text {a }}$, Alexander A. Bachmanov ${ }^{a}$ \\ ${ }^{a}$ Monell Chemical Senses Center, Philadelphia, PA, 19104, USA \\ ${ }^{\mathrm{b}}$ USDA/APHIS National Wildlife Research Center, Fort Collins, CO, 80521, USA
}

Received 24 February 2007; received in revised form 9 August 2007; accepted 20 August 2007

\begin{abstract}
When casein, a milk protein, is hydrolyzed, it renders human foods that contain it (e.g., hypoallergenic infant formula, cheeses) distasteful to many people. This rejection of hydrolyzed casein (HC)-containing foods has recently been found to also occur in a non-human species (deer, Odocoileus spp.). Identifying other animals that avoid HC would facilitate understanding how and why HC-containing food is often rejected. This study determined whether HC-containing food is avoided by Mus musculus and whether consumption patterns were sensitive to testing conditions, specifically food form (powder, pellet or dough) and food access (ad libitum or $1.5 \mathrm{~h} /$ day following $6 \mathrm{~h}$ of food deprivation). Diets were offered in two-choice tests that paired an HC-containing food with an intact casein-containing alternative at seven protein concentrations $(0 \%-50 \% \mathrm{w} / \mathrm{w})$. Five experimental groups were tested under different combinations of food form and food access. Three groups $($ ad lib/powder, ad lib/pellet, and $1.5 \mathrm{~h} /$ pellet) avoided the HC diet starting at the $30 \%$ protein level. At the $40 \%$ and $50 \%$ protein levels, all groups showed strong avoidance of HC. Although testing conditions influenced total caloric intake and body weight gain, avoidance of HC at the highest concentrations was robust to the manipulations in experimental conditions. Our study suggests that mice may be a useful model for understanding the mechanisms of $\mathrm{HC}$ rejection.
\end{abstract}

(C) 2007 Elsevier Inc. All rights reserved.

Keywords: Protein preference; Protein avoidance; Milk protein; Two-choice test; Short-term versus long-term test; Hydrolysate formula; Deer repellent

\section{Introduction}

Casein is one of two major protein fractions in milk, making up about $40 \%$ of the protein in human milk and between approximately $78 \%$ and $86 \%$ of the protein in house mouse, cow, sheep, goat, and buffalo milks [1]. In addition to its value as a nutritional source for young mammals, casein is the source of a number of bioactive peptides with putative antihypertensive, antithrombotic, opioid, immunostimulating, antimicrobial, and nutrient uptake capabilities, which have been established in vitro, yet generally are not well understood in vivo [reviewed in: $2-5]$. In order to exhibit bioactivity, these peptides need to be released from the casein micelle by enzymatic proteolysis, either in the gastrointestinal tract or before ingestion, during food processing. The use of casein hydrolysates to deliver

\footnotetext{
* Corresponding author. Mailing Address: Monell Chemical Senses Center, 3500 Market St., Philadelphia, PA 19104, USA. Tel./fax: +1 2675194763.

E-mail address: kfield@monell.org (K.L. Field).
}

casein-derived peptides is becoming more common in the manufacturing of "functional foods" [6]. For example, LACTIUM $^{\mathrm{TM}}$ (Ingredia, Arras, France) is a bovine $\alpha_{\mathrm{s} 1}$-casein tryptic hydrolysate that is promoted for human consumption to help regulate symptoms of stress. This $\alpha_{\mathrm{s} 1}$-casein tryptic hydrolysate decreased anxiety-related behaviors of rats in conditioned burying and elevated plus-maze tests [7], prevented stressinduced sleep disturbances in rats [8], and reduced the magnitude of stress-induced cortisol and blood pressure responses in humans [9].

Hydrolyzed casein (HC) is also used as a protein source in infant formulas to produce hypoallergenic food for babies with cow's milk allergies, which tend to be induced by intact proteins and not derivative peptides [reviewed in 10-12]. A major problem with using $\mathrm{HC}$ is its distasteful flavor $[13,14]$. Infants older than 4 months, like older children and adults, strongly reject hydrolysate formulas on their first presentation $[15,16]$. Likely, this negative response is due to the bitter and sour tastes and the unappealing smell of the hydrolysate formulas 
described by adults [17]. Sensory panel evaluation of fractions from four different proteolytic casein hydrolysates determined that the predominant taste of $\mathrm{HC}$ is bitter [18]. There has been sustained research efforts devoted towards removing bitter peptides from $\mathrm{HC}$ in order to improve cheese and other food flavor [e.g., 19-23]. Other strategies include masking the hydrolysate with other flavors or, when used as a nutraceutical, encapsulating it (e.g., LACTIUM ${ }^{\mathrm{TM}}$ ).

$\mathrm{HC}$ has also received attention for its possible efficacy in deterring other species from consuming foods humans wish to protect. HC applied topically to salal leaves (Gaultheria shallon) and western redcedar (Thuja plicata) seedlings reduced whitetailed deer (Odocoileus virginianus ochrourus) browsing damage to the treated plants as effectively as a commercial deer repellent [24]. Intact casein and infant formulas (concentrated form, containing $\sim 17 \% \mathrm{HC}$ ) offered plants some protection from deer consumption but were less effective than the pure hydrolysate application, which suggested that both hydrolysis and application at higher concentration were important to HC's repellent effect $[24,25]$. The deer studies did not investigate chemosensory mechanisms responsible for the repellent activity of the HC. Since herbivores encounter plants that taste bitter to humans as a typical component of their foraging environment and herbivores do not necessarily respond to bitter compounds in the same way as omnivores or carnivores [26-28], it is uncertain whether HC alters food characteristics for deer through the same chemosensory modalities and/or tastant components as for humans.

Very little is known about other species' ingestive responses to $\mathrm{HC}$ under free-feeding conditions. At low concentrations (up to $3 \% \mathrm{HC}$ in water), domestic cats and four captive species of Panthera preferred HC solutions to water [29]. Rats given the opportunity to select from three simultaneously offered diets containing protein that differed in the hydrolysis of the casein (intact casein, HC, or amino acid mixture simulating casein's composition) preferred the intact casein diet and ate very little of the HC [30]. These two studies are the only ones to our knowledge that offer other species a choice between a food containing $\mathrm{HC}$ and at least one alternative. In most studies, $\mathrm{HC}$ is fed in no-choice conditions or is force-fed to subjects, neither of which addresses questions concerning how these other animals respond to the sensory properties of $\mathrm{HC}$.

Given that casein and its peptide components continue to stimulate interest in a number of areas including nutraceuticals, food sciences, pediatrics, enteral physiology, and wildlife damage management, assays to determine other species' ingestive responses to $\mathrm{HC}$ would be valuable. Studying the variables controlling ingestive response to $\mathrm{HC}$ would be most easily conducted in a laboratory animal model. However, aside from the work mentioned above, it is unknown whether mammals other than humans, deer, and possibly rats avoid food containing HC.

We chose to investigate laboratory mouse ingestive response to $\mathrm{HC}$ diets. Mice are able to detect the five primary tastes (sweet, salty, bitter, sour, and umami [e.g., 31,32]), and have served as useful model animals for investigation of taste, particularly in studies that have focused on the genetic mechanisms influencing ingestive behavior. As responses to $\mathrm{HC}$ have not yet been described in mice, and there was no background information available that suggested that a particular inbred strain would be more suitable, we selected an outbred strain of Mus musculus (CD-1) for this study.

To determine the effects of $\mathrm{HC}$ on food intake, we tested mice with two diets that were identically formulated except that the protein source differed in the degree of proteolysis (intact casein or HC). Casein was selected as the alternative to its hydrolysate in order to maintain nutritional similarity between the two food options. Ingestive patterns can be altered by the physical form of the diet [33-37], as well as by food deprivation, at least when subjects can select among separate macronutrients and alter the nutritional composition of their meal [38,39]. Context-specific attributes of experimental design (e.g., the particular compositions of offered foods, the available alternatives, the particular food restriction schedules) may produce context-specific results, which have frustrated attempts to identify generalities about how different variables affect intake patterns [40]. In order to evaluate the sensitivity of the intake and preference patterns, we also manipulated two common feeding variables: the physical form of the test diets (powder, pellet, or dough) and availability of the test diets ( $\mathrm{ad}$ libitum or $1.5 \mathrm{~h} /$ day preceded by 6 -h food deprivation period).

\section{Materials and methods}

\subsection{Subjects and experimental groups}

Fifty outbred CD-1 IGS male mice were purchased from Charles River Laboratories, Inc. (Willmington, MA), where they had been fed a casein-free lab chow from weaning. Mice were between 49 and 57 days old at the start of the testing procedure. They were housed individually in opaque plastic cages $(27.5 \mathrm{~cm} \times 17.5 \mathrm{~cm} \times 12 \mathrm{~cm})$ at approximately $23{ }^{\circ} \mathrm{C}$ in a colony room in which the lights were on from 0700 to $1900 \mathrm{~h}$. Deionized water was available continuously.

To determine the effects of the physical form of food and food access conditions on food preference patterns, mice were randomly assigned into five experimental groups $(N=10 /$ group). Each group received the casein and hydrolyzed casein diets in a particular form (powdered, pellets, or dough) with either long-term (ad libitum over $24 \mathrm{~h}$ ) or short-term (1.5 h/day) access conditions. Thus, one group received the diets in powdered form with long-term access (Po-L), while a second group received powdered food with short-term access (Po-S). The third and fourth groups received the diets as pellets, with either long-term or short-term access (Pe-L, Pe-S). The final group received its diets in a moist, dough-like form with short access (Do-S). A corresponding group with long-term access to dough was not possible because the evaporative loss over a 24$\mathrm{h}$ period substantially changed its form.

\subsection{Materials}

\subsubsection{Diets}

The overnight diet for the short-term access groups was Teklad Rodent Diet 8604 (Harlan, Madison, WI; average composition $(w / w)$ : $24.5 \%$ protein, $4.4 \%$ fat, $3.7 \%$ fiber, $7.8 \%$ ash, $46.6 \%$ nitrogen-free energy; $3.3 \mathrm{kcal} / \mathrm{g}$ digestible energy; cereal-based 
Table 1

Composition of test diets

\begin{tabular}{|c|c|c|c|c|c|c|c|}
\hline & \multicolumn{7}{|c|}{ Test diet protein concentration } \\
\hline & $0 \%$ & $5 \%$ & $10 \%$ & $20 \%$ & $30 \%$ & $40 \%$ & $50 \%$ \\
\hline \multicolumn{8}{|l|}{ Ingredient $(\mathrm{g} / \mathrm{kg})$} \\
\hline Protein $^{\mathrm{a}}$ & 0 & 50 & 100 & 200 & 300 & 400 & 500 \\
\hline Cornstarch $^{\mathrm{b}}$ & 548 & 511 & 474 & 400 & 326 & 252 & 178 \\
\hline Dyetrose $^{\mathrm{b}}$ & 192 & 179 & 166 & 140 & 114 & 88 & 62 \\
\hline Sucrose ${ }^{c}$ & 90 & 90 & 90 & 90 & 90 & 90 & 90 \\
\hline Cellulose $^{\mathrm{b}}$ & 50 & 50 & 50 & 50 & 50 & 50 & 50 \\
\hline Soybean oil ${ }^{\mathrm{b}}$ & 70 & 70 & 70 & 70 & 70 & 70 & 70 \\
\hline Salt mix \#210025 ${ }^{b}$ & 35 & 35 & 35 & 35 & 35 & 35 & 35 \\
\hline Vitamin mix $\# 310025^{\mathrm{b}}$ & 10 & 10 & 10 & 10 & 10 & 10 & 10 \\
\hline Soy lecithin ${ }^{\mathrm{d}}$ & 5 & 5 & 5 & 5 & 5 & 5 & 5 \\
\hline \multicolumn{8}{|l|}{ Energy density $(\mathrm{kcal} / \mathrm{g})^{\mathrm{e}}$} \\
\hline Powder \& pellets $(\mathrm{C}, \mathrm{HC})$ & $3.8,3.8$ & $3.8,3.8$ & $3.8,3.8$ & $3.8,3.8$ & $3.8,3.8$ & $3.8,3.8$ & $3.8,3.8$ \\
\hline $\operatorname{Dough}(\mathrm{C}, \mathrm{HC})$ & $3.1,3.1$ & $3.1,3.1$ & $3.1,3.1$ & $3.1,3.2$ & $3.1,3.1$ & $2.9,3.2$ & $2.8,3.2$ \\
\hline
\end{tabular}

diet that does not contain $\mathrm{C}$ or $\mathrm{HC}$ ), which was also used to train the mice during the acclimation period (described below). Table 1 lists the compositions of the $\mathrm{C}$ and $\mathrm{HC}$ experimental diets, which were modeled on the formulation of the American Institute of Nutrition's rodent diet [AIN-93G diet; [41]. All diets were mixed in Hobart N-50 and I-300 mixers (Hobart manufacturing Co., Troy, $\mathrm{OH})$. The resulting powdered diets were either used for the Po-L and Po-S groups, or further processed by adding enough deionized water to allow for adherence into a solid mixture ("dough") that could be rolled out and pressed through a plastic grid to produce small cubes ("pellets"; approximately $1.5 \mathrm{~cm} \times 1.5 \mathrm{~cm} \times 1 \mathrm{~cm})$. Necessary water quantities depended on protein type and concentration (Table 2). Dough cubes were dehydrated into pellets (D10 food dehydrator, The SausageMaker, Inc., Buffalo, NY) at approximately $66.5^{\circ} \mathrm{C}$ and removed when they appeared dry (11.5-20.5 h; time varied with protein type and concentration, ambient humidity and quantity of food simultaneously drying). Dehydrated pellets were left out in ambient conditions for 4-6 days during which weights were monitored and, after assuring that constant weight had been reached, pellets were stored in airtight plastic containers until use with the Pe-L and Pe-S groups. Part of the dough was retained and frozen for later use with the Do-S group.

\subsubsection{Food containers and cage conditions}

Powder and dough diets were presented in 2-oz glass jars (5.3 $\mathrm{cm}$ diameter, $5 \mathrm{~cm}$ height) placed side-by-side in the mouse's home cage at the end opposite from the water access. To reduce spillage and contamination of the powder and dough diets, plastic lids with a $3.2-\mathrm{cm}$ diameter hole drilled into them were placed on the jars, which were placed in square metal spillcatching containers. "Food protectors", constructed from an inverted $0.5-\mathrm{L}$ plastic water bottle with a cutout $7.5 \times 3.5-\mathrm{cm}$ rectangular opening, were slipped over food jars to protect the contents from urine and feces dropping from overhead when mice climbed on cage lid bars. Further, the plastic protectors also reduced spillage by making food removal from the jars to the cage more difficult. For the Pe-L and Pe-S groups, pellets were placed on the cage lid food hopper, which had been divided into two sections $4.2 \mathrm{~cm}$ wide each.

Paper cage liners were used and changed daily in order to collect and quantify food spillage. Spillage was identified by coloring the diets either red or blue (FD\&C Blue 1 aluminum lake, FD\&C Red 40 aluminum lake; International Foodcraft Corporation), which was counterbalanced for diet type within groups and alternated for each individual following each concentration so that diet type could not be associated with color. Each cage contained a metal cup $(8.2 \mathrm{~cm}$ diameter, $4.3 \mathrm{~cm}$ high) and a cotton ball for enrichment and to provide an alternative to sleeping on top of the food jars.

\subsection{Testing procedures}

Although food form and access conditions differed among groups, all mice were tested in two-choice tests that paired a diet containing casein (C) versus one that contained hydrolyzed casein (HC), with the protein concentration of the diet choices being matched. Mice were tested in their home cages with a series of ascending protein concentrations $(0 \%, 5 \%, 10 \%, 20 \%$,

Table 2

Deionized water amounts used to make doughs

\begin{tabular}{lllllllll}
\hline & & \multicolumn{7}{c}{ Test diet protein concentration } \\
\cline { 2 - 9 } & & $0 \%$ & $5 \%$ & $10 \%$ & $20 \%$ & $30 \%$ & $40 \%$ & $50 \%$ \\
\hline Deionized water & $\mathrm{C}$ & 212 & 222 & 235 & 227 & 239 & 304 & 346 \\
(ml/kg powdered diet) & HC & 212 & 216 & 210 & 200 & 212 & 191 & 191 \\
\hline
\end{tabular}


$30 \%, 40 \%, 50 \%$ ) for a 48 -h period per concentration, with no breaks between concentrations. Intake was estimated by the difference in food weight at the end of the access period compared to the beginning, corrected for spillage and for weight changes due to fluctuations in ambient humidity.

The two long-term groups (Po-L, Pe-L) had access to only the experimental diets throughout the duration of the testing series. The position of the $\mathrm{C}$ and $\mathrm{HC}$ diets was switched after $24 \mathrm{~h}$ to control for position biases. Po-L mice were given fresh food when diet positions were switched in order to reduce cumulative contamination that could occur despite the measures to prevent contamination.

Mice in the groups with short-term access were motivated by $6 \mathrm{~h}$ of food deprivation prior to the 1.5 - $\mathrm{h}$ test with the experimental diets. Access to the test diets started at $1500 \mathrm{~h}$ for the Po-S and Pe-S groups, and $1540 \mathrm{~h}$ for the Do-S group. The position of the $\mathrm{C}$ and $\mathrm{HC}$ diets was alternated for each day's short-access test. Following the test session, the short-term test mice received an overnight food ration of $4 \mathrm{~g}$ of powdered Teklad 8604 chow, which was removed the following morning at 0900 (Po-S, Pe-S) or 0940 (Do-S).

Mice were weighed at the time that their cage liner was changed, immediately before their test foods were given, replaced or switched in position. These procedures occurred between 1030 and $1134 \mathrm{~h}$ for the long-term groups and 1428 and $1540 \mathrm{~h}$, during the final half-hour of their 6-h deprivation, for the short-term groups.

Prior to starting the two-choice tests, mice were given a 9day acclimation period, which allowed them to gain experience with the food containers, food forms and, for the short-term groups, the food deprivation schedule. This acclimation period included 2 days recovery upon arrival at our facility, during which they were given Teklad 8604 chow pellets in cage lid feeding hoppers. All groups that were scheduled to receive powdered food during the testing, either as the test diet form (Po-L, Po-S) or for their overnight ration (Do-S, Pe-S), received powdered Teklad 8604 diet in glass jars during acclimation days 3 and 4 (Pe-L mice continued to get Teklad 8604 pellets). On acclimation days $5-9$, mice were introduced to food protectors, divided cage lid hoppers, nest cups, and paper cage lining. Additionally on days 5-9, the short-term access groups received the overnight 4-g ration of Teklad 8604 chow/6$\mathrm{h}$ deprivation/1.5-h testing schedule using the food form they would experience during testing (e.g., Do-S received moistened Teklad 8604 powder (1:1 DI water to chow) patted into a "dough" ball for $1.5 \mathrm{~h}$ following 6-h deprivation and powdered Teklad 8604 overnight). By the time testing started, only the experimental diets themselves were novel to the subjects. Thus, the experimental schedule comprised 9 days acclimation followed by 15 days testing of $\mathrm{C}$ versus $\mathrm{HC}$ diets over a range of increasing protein concentrations. Logistical considerations required testing to be conducted on no more than three groups simultaneously, so the Po-L and Po-S groups were tested first, followed by the testing of the remaining three groups.

\subsection{Data analysis}

We used body weights ( $\mathrm{g}$ ), total food intake (kcal) and response to $\mathrm{HC}$ (kcal intake and proportion of total diet) to determine whether mice discriminated between foods containing $\mathrm{HC}$ and $\mathrm{C}$ and if testing conditions affected these intake patterns. Body weights (BW) were compared among groups at two time points (beginning and end of the testing series) using a repeated-measures (RM) analysis of variance (ANOVA) that modeled test group as a between-subjects factor and test day (on which BW was measured) as a within-subjects factor. Results suggested that there were differences in the amount of weight gained by mice in different groups over the course of testing, which stimulated a follow-up analysis. To examine the possible group effect on BW gain, we conducted a one-way ANOVA on the difference between initial and final BWs, expressed as a percentage of the initial BW.

Because of the variation in $\mathrm{BW}$ among testing groups, we adjusted individual food intake values by BW for all intake comparisons. Specifically, each subject's 48-h intake value in kcal for each protein concentration was divided by his mean BW for those 2 days of testing at that concentration, and then multiplied by $30 \mathrm{~g}$ (which was used as the size of a representative mouse), and finally divided in half to arrive at an estimate for kcal intake over $24 \mathrm{~h}$, adjusted for BW. Total food intake was examined using two measures: a) average total daily intake, which for the longaccess groups, included the caloric intake from the test diets (with no discrimination between the $\mathrm{HC}$ and $\mathrm{C}$ intake) and, for the short-access groups, included the caloric intake from the test diets and the overnight Teklad 8604 ration, and b) total test food intake, which included only the $\mathrm{HC}$ and $\mathrm{C}$ that was consumed during the test access periods $(24 \mathrm{~h}$ or $1.5 \mathrm{~h})$. Analyses of total food intake included all tested diets ( $0-50 \%$ protein concentrations).

Total food intake was analyzed in order 1) to pursue whether the observed difference in BW gains could be associated with differences in consumption, and 2) to investigate the possibility that food form affected intake patterns within each access condition. To achieve the first goal, we used a one-way ANOVA model to compare the average total daily intake values (averaged over all concentrations) of the five experimental groups. The association between BW and caloric intake was further examined through a regression model of $\% \mathrm{BW}$ gain as a function of daily caloric intake using individual intake values. As the final part of the analysis of intake's relevance for explaining group differences in \% BW gain over the study, we focused on test foods only and compared the average caloric intake of the test diets to the caloric intake of Teklad 8604 chow, which had been presented under identical conditions as the test diets on the last day of the acclimation period. This was done by using a RM ANOVA model with groups as the betweensubjects factor and diet type (acclimation intake of chow and average intake of test diets over all concentrations) as the within-subjects factor. Lastly, to achieve the second goal of our larger total intake analysis, we analyzed the total test food intake of the long-access and short-access groups separately due to differences in the duration during which diets were available ( $24 \mathrm{~h}$ versus $1.5 \mathrm{~h}$ ) using two RM ANOVAs (with group as a between-subjects factor and protein concentration as a withinsubjects factor).

Finally, we analyzed $\mathrm{HC}$ intake (kcal) and the proportion of total intake comprising $\mathrm{HC}$ (proportion scores) using only the 
Table 3

Body weight (g) at $0 \%$ concentration testing ("start") and after 50\% concentration testing ("end"), \% body weight gained over testing (g gained also shown), and daily total food intake ( $\mathrm{kcal} / 24 \mathrm{~h}$ ); means (SDs), see text for explanation of groups

\begin{tabular}{llllll}
\hline Group & BW-start & BW-end & g BW gain & \% BW gain & kcal/24 h \\
\hline Po-L & $33.8(1.9)^{\mathrm{a}}$ & $36.4(2.9)^{\mathrm{a}}$ & $2.5(1.4)$ & $7.4(4.0)^{\mathrm{c}}$ & $17.0(0.8)^{\mathrm{b}}$ \\
Pe-L & $31.6(1.3)^{\mathrm{a}, \mathrm{c}}$ & $33.4(1.4)^{\mathrm{a}, \mathrm{c}}$ & $1.8(1.3)$ & $5.6(4.3)^{\mathrm{c}}$ & $17.3(1.2)^{\mathrm{a}, \mathrm{b}}$ \\
Po-S & $30.2(1.4)^{\mathrm{a}, \mathrm{b}}$ & $34.7(2.8)^{\mathrm{a}, \mathrm{b}}$ & $4.5(1.7)$ & $14.7(5.3)^{\mathrm{b}}$ & $18.2(1.1)^{\mathrm{a}, \mathrm{b}}$ \\
Pe-S & $27.4(1.4)^{\mathrm{b}}$ & $32.5(2.2)^{\mathrm{b}, \mathrm{c}, \mathrm{d}}$ & $5.1(1.4)$ & $18.7(5.1)^{\mathrm{a}, \mathrm{b}}$ & $18.4(0.6)^{\mathrm{a}}$ \\
Do-S & $28.1(1.2)^{\mathrm{b}, \mathrm{c}}$ & $34.4(1.8)^{\mathrm{a}, \mathrm{d}}$ & $6.4(1.5)$ & $22.7(5.3)^{\mathrm{a}}$ & $18.3(1.2)^{\mathrm{a}}$ \\
\hline
\end{tabular}

Group means within a column that do not share any common letters significantly differ (Tukey HSD tests; $p<0.05$ ), while those labeled with at least one letter in common do not.

${ }^{\#}$ Long-access groups $=\mathrm{HC}+\mathrm{C}$ diets; Short-access groups $=\mathrm{HC}+\mathrm{C}+$ overnight Teklad 8604 chow; averaged over entire testing period ( $0 \%-50 \%$ concentrations).

protein-containing diets $(5-50 \%$ conc). Both analyses were conducted with RM ANOVA models with groups as betweensubject and protein concentration as within-subject factors. For caloric intake, we ran the long-access and short-access groups in separate statistical models since kcal would vary dramatically and predictably among these groups simply due to the difference in imposed durations available for eating. HC intake was also compared to $\mathrm{C}$ intake for all groups for all protein-containing concentrations by using 30 paired-sample Student $t$-tests and controlling the experiment-wise error rate $\leq 0.05$ (Dunn-Sidak technique, $\alpha^{\prime}=0.0017$ [42]). Significant differences between HC and $\mathrm{C}$ intake were considered evidence for preference or avoidance of $\mathrm{HC}$, depending on the direction of the intake asymmetry. Thresholds were defined as the lowest concentration at which preference or avoidance was detectable. HC proportion scores were analyzed in a RM ANOVA model with group as the betweensubjects and concentration as the within-subjects factors on arcsin square root transformed proportions, which provided a better fit to the model's distribution assumptions than did the raw data. Follow-up one-way ANOVAs at each of the six protein-containing concentrations were used to examine how group proportion scores (arcsin square root transformed) varied within each protein level. We adjusted the alpha level on this series to account for the multiple comparisons (Dunn-Sidak technique, $\alpha^{\prime}=0.0085$ ).

Statistical analyses were conducted using Statistica 6.1 (StatSoft, Inc., Tulsa, OK, USA). For the within-subject effects in the RM ANOVA models, the sphericity assumption was assessed with a Mauchley Sphericity test and, if significant results indicated violations of this assumption, multivariate results using Pillai's adjusted degrees of freedom and $F$-value were presented. Post-hoc comparisons for ANOVAs were conducted using Tukey's honestly significant difference (HSD) test. Figures depict untransformed data.

\section{Results}

\subsection{Body weight $(B W)$}

Examination of the initial (start of the $0 \%$ protein diets) and final (completion of the $50 \%$ protein diets) days of testing revealed that mean BW increased over the course of testing, although the magnitude of increase depended on the test group type (Group: $F(4,45)=11.41$, Test Day: $F(1,45)=380.02$, Group $\times$ Test Day: $F(4,45)=16.57$, all $p$-values $<0.001)$. On the initial day, the mice in the Po-L group were heavier than in two of the short-term access groups (Pe-S, Do-S), and mice from the Pe-L group were heavier than mice from the Pe-S (Table 3), indicating that overall BW tended to be higher in groups with long-term food access than in groups with shortterm access. This weight variation likely reflects both the differences in testing procedures and small age differences of mice among groups. Access to the foods (long versus short) likely influenced the starting BWs, since the short-access mice were required to habituate to the food restriction schedule. Additionally, these short-access mice were fasted when weighed, and thus had less food in their digestive tracts than non-restricted mice. Further, the first two groups that were tested (Po-L, Po-S) were slightly older (6-8 days), and thus slightly heavier, than the remaining mice when they were shipped to our facility.

On the final day, the Po-L mice were still heavier than the Pe$\mathrm{S}$ mice (Table 3). However, all other pair-wise group comparisons revealed no differences. This interaction between group and test day suggested that some groups gained more weight throughout the testing than other groups. When BW gain was examined as a percentage of initial weight, we did find group differences $(F(4,45)=22.79, p<0.001$, Table 3$)$. Each of the three short-access groups had significantly higher BW gain than did each of the two long-access groups. Within the shortaccess groups, the Do-S mice had significantly greater BW gain than did mice from the Po-S group.

Although it was possible that food restriction or exposure to the experimental diets would challenge the mice's ability to maintain or gain weight, we found, on the contrary, all but two subjects gained weight over the course of testing. These BW data indicate that our subjects were able to accommodate the experimental conditions used in the study.

\subsection{Total food intake}

The greater BW gain of the short-access groups relative to the long-access groups suggested that a restricted feeding schedule may increase total daily food intake in comparison to ad libitum feeding conditions. Consistent with this hypothesis, groups did differ in their total daily caloric intake $(F(4,45)=$ $3.89, p=0.009$ ). Mice with ad libitum access to food tended to consume less energy than mice from the short-access groups, although not all differences in pair-wise long- and short-access groups were significant (Table 3). This relationship is also evident from the significant linear regression of $\% \mathrm{BW}$ gain on total daily intake (adjusted $R^{2}=0.45 ; F(1,48)=41.86$, $p<0.001 ; y=-0.727+0.049 x$ ). When total test food intake, averaged across all tested concentrations, was compared to chow intake on the last day of the acclimation period, intake differed depending on group type and whether the diet was Teklad 8604 chow or the test diets, but in a non-additive pattern (Group: $F=620.3, p<0.001$; diet type: $F=4.796, p=0.034$; group $\times$ diet: $F=12.939, p<0.001)$. Mice from both long-access 

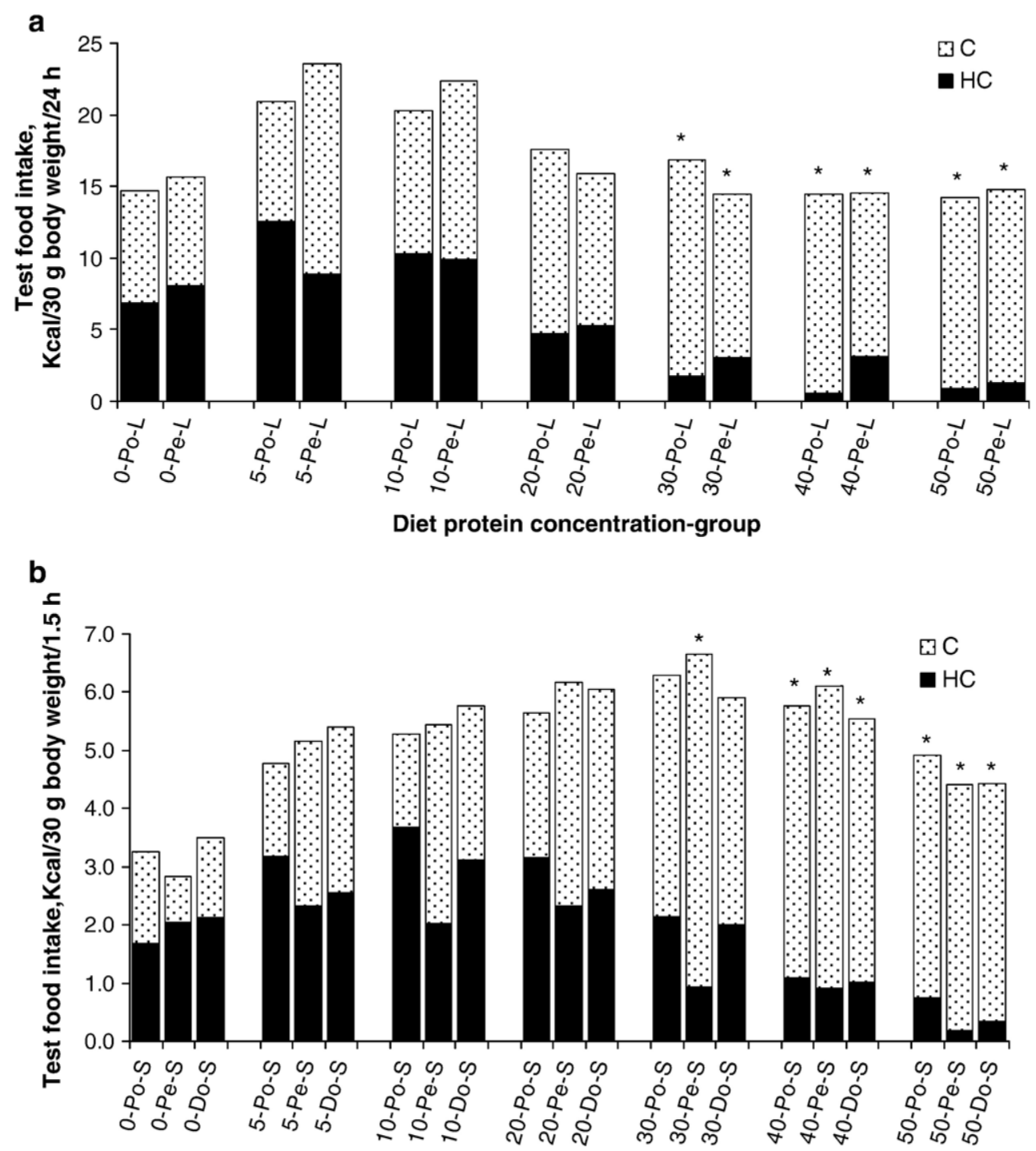

Diet protein concentration-group

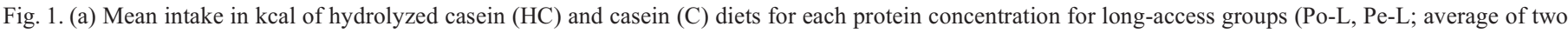

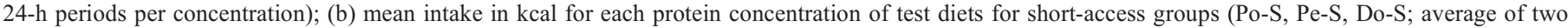

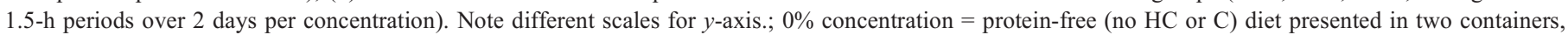

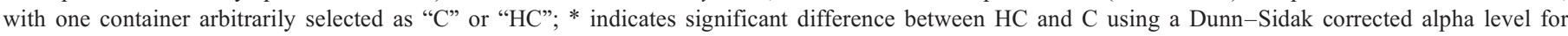
multiple comparisons ( $\alpha^{\prime}=0.0017$ for 30 comparisons).

groups ate less of the test diet relative to the amount of chow they consumed, while mice from all of the short-access groups ate more test diet than chow. However, only for three groups were the test food intake values significantly lower (Pe-L) or higher (Pe-S, Do-S) than chow intake (Tukey HSD, $p$ values $<0.02)$. Together, these three lines of evidence demonstrate that the greater BW gains of the food restricted mice through the course of the study were due to their increased caloric intake.

The second goal of our total food intake analysis was to determine whether testing conditions affected total test food $(\mathrm{HC}+\mathrm{C}$ diet) intake. For the long-access groups, whether the diet was given as powder or as pellets did not matter per se (Group: $F(1,18)=0.504, p=0.49$ ), but test food intake did vary over concentration, in a manner that was dependent on group type (Conc: Pillai's corrected $F(6,13)=40.14, p<0.001$, Con$\mathrm{c} \times$ Group: Pillai's corrected $F(6,13)=4.41, p=0.01)$. Fig. 1a depicts the test food intake of the long-access groups. Intake at $0 \%$ concentration was similar to intakes at 30-50\%, which were all lower than intake at 5\% and 10\% (Tukey HSD, significant $p$ values all $<0.05)$. Although there were no differences between the Po-L and Pe-L intakes at any single protein concentration, the significant interaction between concentration and group occurred because the Pe-L group tended to be higher than the Po-L group at $0-10 \%$, but lower than the Po-L group at 20 $30 \%$ protein levels.

For the short-access groups (Fig. 1b), the only significant effect on total test food intake was protein concentration (Group: $F(2,27)=0.05, p=0.95$; Conc: Pillai's corrected $F$ $(6,22)=46.21, p<0.001$, Conc $\times$ Group: Pillai's corrected $F$ 


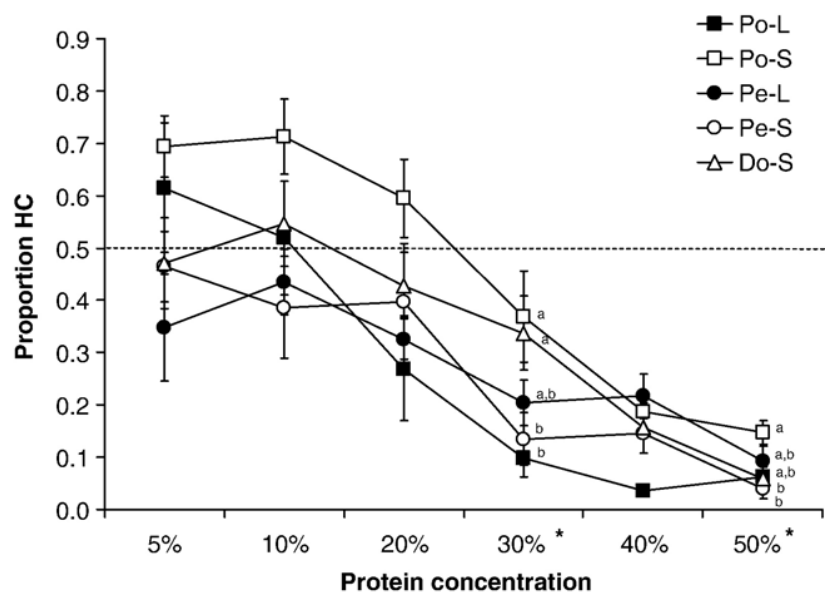

Fig. 2. Proportion intake of $\mathrm{HC}$ diets at different concentrations for five experimental groups (Mean $\pm \mathrm{SE}$ ), see text for explanation of groups; * indicates that significant group differences were found at these concentrations in followup one-way ANOVAs $\left(\alpha^{\prime}=0.0085\right.$ for 6 comparisons $)$ - groups sharing the same letter do not differ from one another (Tukey's HSD, $p<0.05$ ).

$(12,46)=1.39, p=0.20)$. The short-access groups had significantly lower intake at $0 \%$ concentration than at any of the other concentrations (Tukey's HSD pair-wise comparisons, significant $p$-values $<0.05$ ). Intake increased until $30 \%$ protein levels, then began to decrease such that the intake at $50 \%$ was similar to the intake at $5 \%$ concentration (Fig. 1b). Other than at $0 \%$ and $50 \%$ levels, intake at any particular concentration in the shortaccess groups was not significantly different than the intake for at least one neighboring concentration, indicating the gradual rate of change over the concentration gradient (based on Tukey's HSD pair-wise comparisons; Fig. 1b). When comparing the short-access groups to the long-access groups, there was a subtle difference in the patterns. The long-access groups' total test diet intake values were higher at the $5 \%$ and $10 \%$ diets compared to the other concentrations, which all had similar values.

In summary, the daily caloric intake and total test food versus chow intake analyses suggest that the greater BW gain during the study of the short-access group mice was due to a higher daily caloric intake. Access conditions also influenced test food intake patterns over the tested concentrations. In contrast, the form in which diets were presented had little effect on total intake patterns.

\subsection{HC response: intake and diet choice}

Examination of the intake of protein-containing $(5 \%-50 \%)$ diets in the long-term access groups (Fig. 1a, solid portion of bars) determined that $\mathrm{HC}$ diet intake (kcal) was similar for the Po-L and Pe-L groups (group effect: $F(1,18)=0.006, p>0.05$ ) and that overall increasing protein concentration decreased $\mathrm{HC}$ intake (concentration effect: Pillai's adjusted $F(5,14)=11.01$, $p<0.001)$, although the effect of concentration was dependent on group type (Conc $\times$ Group effect: Pillai's adjusted $F(5,14)=$ $5.71, p=0.004)$. At the $5 \%$ concentration, the Po-L group tended to have greater $\mathrm{HC}$ intake than the Pe-L group, yet at $30-$ $40 \%$ concentrations the reverse tended to be true.
The short-term access groups (Fig. 1b, solid portion of bars) showed a significant decrease in kcal of $\mathrm{HC}$ diet intake as concentration increased (Pillai's adjusted $F(5,23)=24.509$, $p<0.001)$ and no differences among groups $(F(2,27)=2.27$, $p=0.13)$ or interaction between group and concentration $(F(10,48)=$ $1.23 ; p=0.297)$. In these three groups, HC intake was similar and highest in the $5 \%-20 \%$ protein diets, intermediate in the $30 \%$ diet, and lowest at the $40-50 \%$ levels (Tukey HSD, significant $p$ values $<0.05$ ).

We identified significant differences between the $\mathrm{HC}$ and $\mathrm{C}$ intake values at each protein concentration for each group. At the tested protein concentrations, no group exhibited a preference for HC. Avoidance, defined as significantly lower $\mathrm{HC}$ intake compared to $\mathrm{C}$ intake, was first identified at the $30 \%$ protein diets for the two long-access groups (Po-L, Pe-L) and for Pe-S. The remaining groups, Po-S and Do-S, first avoided $\mathrm{HC}$ at the $40 \%$ protein levels (Fig. $1 \mathrm{a}$ and $\mathrm{b}$ ).

When we examined the proportion of $\mathrm{HC}$ diet consumed (proportion scores), we found that it was significantly affected by group type, protein concentration and their interaction (Group: $F(4,45)=2.88, p=0.03$; Concentration: Pillai's adjusted $F(5,41)=36.25, p<0.001$; Concentration $\times$ Group: Pillai's adjusted $F(20,176)=2.7, p<0.001)$. The interaction between testing group and protein concentration is illustrated by results of follow-up one-way ANOVAs at each concentration, which showed no significant group differences at $5 \%$ to $20 \%$ protein levels but significant group differences at $30 \%$ and $50 \%$ levels $(F(4,45) \geq 4.54, p \leq 0.004$; significant after the Dunn-Sidak correction for multiple comparisons, alpha $=0.0085)$. Effect of group at $40 \%$ protein concentration $(F(4,45)=3.38, p=0.017)$ did not reach the significance threshold corrected for multiple comparisons. This interaction can also be characterized by the changing patterns of group differences at different concentrations. At $30 \%$ protein level, the Po-L and Pe-S groups had significantly lower proportion scores than the Do-S and Po-S groups, while the Pe-L group was intermediate in its scores and not significantly different from the other four groups (Tukey HSD, $p<0.05$, Fig. 2). At the $40 \%$ protein level, it is possible that group differences may have been obscured by a Type II error due to the corrected alpha level used as the significance criterion, in which case the post-hoc tests would have revealed that the Po-L group's proportion scores were significantly lower than those of the Po-S and Pe-L groups. At 50\%, the Po-S group had higher scores than the Pe-S group and now also had higher scores than the Do-S scores, which were similar to the Pe-S scores. At HC concentrations avoided by mice, Po-L had significantly lower proportion scores and Po-S had significantly higher scores than at least one of the other groups. These data suggest that neither test access duration nor food format per se has strong, consistent effects on mouse response to HCcontaining food, but that there is a modest effect of the specific combinations of these two factors.

\section{Discussion}

Our results have shown that the intake of an HC-containing diet decreases as the $\mathrm{HC}$ content in the diet increases. Avoidance 
thresholds for $\mathrm{HC}$, relative to $\mathrm{C}$, were demonstrated for a diet containing $30 \%$ protein for three mouse groups (Po-L, Pe-L and Pe-S). When the $30 \% \mathrm{HC}$ proportion scores of these three groups were compared, they were no different from each other, yet they were significantly lower than the scores from the Po-S and Do-S groups at this concentration. All five groups of subjects avoided the $40 \% \mathrm{HC}$ diet, and there were no statistically significant differences in their $\mathrm{HC}$ proportion scores. At the highest $\mathrm{HC}$ concentration (50\%), which provoked universal avoidance by subjects, the Po-S continued to exhibit greater HC proportion scores than did some other groups (Pe-S and Do-S). Overall, these results suggest that food containing $30 \% \mathrm{HC}$ will be avoided by mice under some conditions, and that food containing $40 \%$ or more $\mathrm{HC}$ will be avoided by mice under a wide range of conditions.

The testing conditions we examined in our study (long and short access to the diets, and powder, pellet and dough diet forms) had subtle effects, which were apparent for only some of the dependent variables. When examining caloric intake of the $\mathrm{HC}$ diet, mice given powdered diet showed a steeper decrease in intake over the increasing concentration gradient than did the mice fed pellets, but only in the long-access groups. Perhaps the powdered $\mathrm{HC}$ diet was more appealing than the $\mathrm{HC}$ pellets at low concentrations, which then stimulated a higher starting intake level from which the Po-L mice then dropped. Both pellet groups (Pe-L, Pe-S) first avoided the $\mathrm{HC}$ diet at $30 \%$ protein concentration, hinting that pellets may be more sensitive for discriminating $\mathrm{HC}$ from $\mathrm{C}$ compared to other diet forms (Do-S and Po-S had $40 \%$ avoidance thresholds). However, the Po-L group avoided the $\mathrm{HC}$ diet at $30 \%$ concentration, as well. This could similarly be used to provide tentative support for the idea that access also influences sensitivity to $\mathrm{HC}$ since both longaccess groups (Pe-L, Po-L) had more sensitive thresholds than two of the short-access groups (Po-S, Do-S; 40\% threshold). Altogether, the effects of access conditions and food form on mouse response to HC-containing diets appear to be weak and to interact in unique ways. For example, Po-S was the only group that, through consistently higher HC proportion scores relative to the other groups' scores, tended to distinguish itself from the other groups. Po-S mice's slightly reduced sensitivity to HC's negative properties could be due to a unique interaction between a powdered diet and a food restricted experimental schedule.

Although food access conditions had little effect on $\mathrm{HC}$ response, they did have consequences for general feeding behavior. The long-access groups showed similar caloric intake at all concentrations of test diets except for the $5 \%$ and $10 \%$ levels, in which case caloric intake was elevated. In contrast, the short-access groups had a reduced intake of the protein-free diets compared to the other concentrations, then gradually increased intake over the 5\%-30\% ranges, and then, at $50 \%$, returned to levels similar to those shown at 5\%. Likely these differing patterns in caloric intake over the course of testing reflect inadvertent consequences of the access conditions. The long-access groups would have been protein deprived during the $0 \%$ testing, and the diets for the subsequent two protein concentrations would have contained sub-optimal protein levels. A possible explanation for the increased intake during the $5 \%$ and $10 \%$ concentrations is that long-access mice were trying to compensate for their low protein levels by increasing the quantity of food consumed, in order to ingest more protein. The short-access groups were not dependent on the test diets for their entire nutritional requirements as they had access to $4 \mathrm{~g}$ of complete diet every night. The short-access groups did not show the same intense elevation of intake for the $5 \%$ and $10 \%$ concentrations. Instead, the short-access groups showed an initially low, compared to all other concentrations, intake of the $0 \%$ protein and then a gradual increase of intake over the intermediate concentrations. This pattern would be consistent with these subjects slowly becoming better adjusted to the feeding schedule and, with time, more able to ingest greater amounts in a given short period in anticipation of a predictable restriction regime [43]. The depression of intake for the proteinfree diets could have been the result of novelty, combined with any ongoing physiological adjustments to the restriction schedule. The short-term access mice may have needed several of their brief testing periods to become familiar with the new diets. Consistent with the idea that the short-access mice gradually increased their test food intake as a consequence of increased physiological ability to accommodate their restriction schedule are our findings that short-access mice gained more weight over the experiment than their long-access counterparts. Since the tendency for short-access mice to eat more than longaccess mice was based on intake averaged over concentrations, it is unclear how much of this increased daily intake was due to physiological adjustment to the restricted feeding schedules over time. Another possibility, which is not mutually exclusive, is that the increased intake of the test diets was due to the availability of a greater variety of food options (test foods + chow compared to ad lib access of only test foods), as variety per se has been reported to increase intake [reviewed in 44]. Although we can only speculate on the mechanisms, we can conclude that there was some evidence that our experimental access conditions, but not food form, influenced general feeding behavior and body condition.

This study is the first demonstration that $\mathrm{HC}$ is avoided by mice, which is consistent with the responses of the few other species that have been offered HC-containing food as a dietary choice. White-tailed deer consumed virtually none of the diet containing $\mathrm{HC}$ when they were permitted to choose among a $10 \% \mathrm{HC}$-containing diet, a $10 \% \mathrm{C}$ diet and a protein-free diet in 30-min tests following 6-h food deprivation, which was repeated daily for 16 days [24]. In this study, offering the deer only the HC-containing diet for 8 days did not result in increased intake during this period compared to initial levels, nor did it change the deer's preferences in the three-choice follow-up testing. Although the deer demonstrated a strong preference for the protein-free base diet in the three-choice tests, they consumed the $\mathrm{C}$ diet and clearly preferred it to the $\mathrm{HC}$ diet. In humans, parallel comparisons of intake or taste of simultaneously available $\mathrm{HC}$ - and C-containing foods are not available. However, based on the response of infants older than 4 months to casein hydrolysate infant formula and of adult sensory panel evaluation of the formula, it is clear that humans 
can detect and find disagreeable formulas that contain only $2 \%$ hydrolyzed casein [15-17]. Evidence from laboratory rats also suggests that this species avoids HC-containing foods. Even when investigators deliberatively tried to make the HC diet (16$20 \%$ concentration) more similar to the alternatives (an amino acid mixture containing diet and a $\mathrm{C}$ diet) by adding a bananaflavored aromatic additive to all of the choices, the rats preferred the $\mathrm{C}$ diet over the others and consumed a very small fraction, if any, of their intake as $\mathrm{HC}$ diet [30].

The relatively low concentrations of $\mathrm{HC}$ used in these studies with other species suggest that mice may be less sensitive to negative characteristics of $\mathrm{HC}$ than are these other species. An experiment specifically designed to compare the sensitivity among species would be needed to address this hypothesis. Making meaningful comparisons among species from studies using different experimental conditions is difficult, at best. In addition to many other variables, the mere identity of the alternative option in a two-choice test will unavoidably affect the outcome of this type of test. For example, a food or compound may be avoided at a low concentration when paired with a highly appealing alternative, but avoided at a much higher concentration when paired with a less appealing option.

It is possible that intact casein was itself not an attractive protein source and that we were requiring the mice to choose between two distasteful diets that would then affect our interpretation of HC's ability to alter consumption of foods containing it. When intact casein has been offered to rodents, there have been some reports that individuals have refused to eat it, even to the extent of suffering weight loss and death [e.g., 45-47]. Yet other individuals or strains, sometimes in these same studies that report extreme dislike of casein, readily ate this protein [e.g., 48,45,47], which is one of the most frequently used proteins in purified diets and in macronutrient selection experiments. As results are hard to generalize beyond the specific testing conditions used, it is impossible to know $a$ priori what type of ingestive response subjects will show towards casein. However, even if both options had been distasteful to our subjects, finding an avoidance of the HCoption under these conditions suggests that an HC-containing food would be even more strongly avoided if a more appealing alternative than the $\mathrm{C}$ diet had been available.

As the mice in this study were tested over multiple, relatively natural eating bouts, and sensory properties of the diets were not isolated from their nutritive properties, it is reasonable to assume that post-ingestive feedback might have contributed to the subjects' intake decisions. Although $\mathrm{C}$ and $\mathrm{HC}$ have equivalent nutritive value, there is some evidence that the postingestive effects of $\mathrm{HC}$ can differ from those produced by $\mathrm{C}$. Gastrointestinal transit time in rats was slower with a meal containing casein than for one containing hydrolyzed casein, which may be due to opioid activity of peptides released during in vivo digestion of casein [49]. In humans, there was no difference in the gastric emptying rate between casein and hydrolyzed casein solutions, but there was faster intestinal amino acid absorption for the $\mathrm{HC}$ solution, which produced more gastric secretion and induced a greater amount of glucosedependent insulinotropic polypeptide [50]. In piglets, the reverse was found: no effect of the proteolysis of casein on amino acid absorption [51] but the suggestion that casein was slower to leave the stomach [52]. Nitrogen absorption of a HCcontaining diet was higher than for a C-containing diet for mice maintained on a protein-poor diet $(5.2 \%)$, although not for mice maintained on a complete diet (22.6\% protein) [53].

The evidence that HC may offer nutritional benefits via a shorter gastrointestinal transit time and/or an increased rate of amino acid absorption compared to the intact protein has stimulated the hypothesis that animals should choose HCcontaining foods over C-containing ones when nutritionally compromised. In the study mentioned earlier that offered HC-, $\mathrm{C}$ - and free amino acid diets simultaneously to rats, Ribeiro et al. [30] did not find support for this hypothesis when explicitly testing it with malnourished, enterectomized, and normalcontrol groups. Regardless of nutritional condition, rats showed strong avoidance of the $\mathrm{HC}$ diet relative to the $\mathrm{C}$ diet. An alternative hypothesis to $\mathrm{HC}$ being beneficial for nutritionally compromised individuals is that HC's more easily or quickly absorbed nutrient load, especially at higher protein concentrations, would actually be a deterrent because of its potentially greater disruption to homeostatic systems [43]. High protein levels have been shown to decrease intake levels, although the role of sensory versus post-ingestive feedback is far from being understood [e.g., 54,55].

Whether $\mathrm{C}$ and $\mathrm{HC}$ do in fact provide distinguishable postingestive feedback capable of influencing feeding decisions has not been specifically tested. Doing so by using, for example, a conditioned preference/aversion paradigm, would provide the basis for hypotheses proposing that one or the other should be preferentially selected for nutrient-related physiological benefits. In contrast to the lack of conclusive evidence for postingestive processes influencing selection between casein and its hydrolysate, there are many known reports of the unappealing sensory properties of $\mathrm{HC}$ to humans, which point to a predominantly sensory explanation for $\mathrm{HC}$ avoidance as being the most parsimonious.

Despite much work having been done on casein hydrolysate to date, there remain many unanswered questions about how and why it reduces the appeal of food. Our study found that regardless of testing conditions, mice avoided foods containing $40 \%$ or more $\mathrm{HC}$. This suggests that mice have the potential to be used as a model system to facilitate inquiries in this area.

\section{Acknowledgments}

Stanley Lewis and Mallory Garnett provided invaluable assistance with running the experiment, and the comments of anonymous reviewers improved the manuscript. This project was funded by the U.S. Department of Agriculture's Cooperative Agreement (\#07-7442-0585-CA) between the National Wildlife Research Center and Monell Chemical Senses Center. National Institutes of Health postdoctoral fellowship (\#2 T32 DC 00014-26) supported KLF, NIH R01 grant (HD 37119-06) supported JAM, and NIH R01 grant (DC00882) supported $\mathrm{AAB}$ and GKB. Procedures were approved by Monell's 
Institutional Animal Care and Use Committee (Protocol \#961C).

\section{References}

[1] Fox PF, Guinee TP, Cogan TM, McSweeney PLH. Chapter 3: chemistry of milk constituents. Fundamentals of cheese science. Gaithersburg, MD: Aspen Publishers; 2000. p. 19-43.

[2] Shah NP. Effects of milk-derived bioactives: an overview. Br J Nutr 2000;84(Suppl 1):S3-S10.

[3] Meisel H. Overview on milk protein-derived peptides. Int Dairy J 1998;8:363-73.

[4] Meisel H. Multifunctional peptides encrypted in milk proteins. Biofactors 2004;21:55-61.

[5] Silva SV, Malcata FX. Caseins as source of bioactive peptides. Int Dairy J 2005;15:1-15.

[6] Korhonen H, Pihlanto A. Bioactive peptides: production and functionality. Int Dairy J 2006;16:945-60.

[7] Violle N, Messaoudi M, Lefranc-Millot C, Desor D, Nejdi A, Demagny B, Schroeder H. Ethological comparison of the effects of a bovine alpha s1-casein tryptic hydrolysate and diazepam on the behaviour of rats in two models of anxiety. Pharmacol Biochem Behav 2006;84:517-23.

[8] Guesdon B, Messaoudi M, Lefranc-Millot C, Fromentin G, Tome D, Even PC. A tryptic hydrolysate from bovine milk alphas 1-casein improves sleep in rats subjected to chronic mild stress. Peptides 2006;27:1476-82.

[9] Messaoudi M, Lefranc-Millot C, Desor D, Demagny B, Bourdon L. Effects of a tryptic hydrolysate from bovine milk alpha(s1)-casein on hemodynamic responses in healthy human volunteers facing successive mental and physical stress situations. Eu J Nut 2005;44:128-32.

[10] Hays T, Wood RA. A systematic review of the role of hydrolyzed infant formulas in allergy prevention. Archives of Pediatrics \& Adolescent Medicine 2005;159:810-6.

[11] Host A, Halken S. Hypoallergenic formulas-when, to whom and how long: after more than 15 years we know the right indication! Allergy 2004;59(Suppl 78):45-52.

[12] Osborn DA, Sinn J. Formulas containing hydrolysed protein for prevention of allergy and food intolerance in infants. Cochrane Database Syst Rev 2003 CD003664.

[13] Pedrosa M, Pascual CY, Larco JI, Esteban MM. Palatability of hydrolysates and other substitution formulas for cow's milk-allergic children: a comparative study of taste, smell, and texture evaluated by healthy volunteers. J Investig Allergol Clin Immuno 2006;16:351-6.

[14] Sawatzki G, Georgi G, Kohn G. Pitfalls in the design and manufacture of infant formulae. Acta Paediatr, Suppl 1994;402:40-5.

[15] Mennella JA, Beauchamp GK. Developmental changes in the acceptance of protein hydrolysate formula. J Dev Behav Pediatr 1996;17:386-91.

[16] Mennella JA, Griffin CE, Beauchamp GK. Flavor programming during infancy. Pediatrics 2004;113:840-5.

[17] Mennella JA, Beauchamp GK. Understanding the origin of flavor preferences. Chem Senses 2005;30(Suppl 1):i242-3.

[18] Maehashi K, Matsuzaki M, Yamamoto Y, Udaka S. Isolation of peptides from an enzymatic hydrolysate of food proteins and characterization of their taste properties. Biosci, Biotechnol, Biochem 1999;63:555-9.

[19] Singh TK, Young ND, Drake M, Cadwallader KR. Production and sensory characterization of a bitter peptide from beta-casein. J Agric Food Chem 2005;53:1185-9.

[20] Saha BC, Hayashi K. Debittering of protein hydrolyzates. Biotechnol Adv 2001;19:355-70.

[21] Hill RD, v. Leeuwen H. Bitter peptides from hydrolysed casein coprecipitate. Aust J Dairy Technol 1974;29:32-4.

[22] FitzGerald RJ, O'Cuinn G. Enzymatic debittering of food protein hydrolysates. Biotechnol Adv 2006;24:234-7.

[23] Matoba T, Nagayasu C, Hayashi R, Hata T. Bitter peptides in tryptic hydrolysate of casein. Agric Biol Chem 1969;33:1662-3.

[24] Kimball BA, Nolte DL, Perry KB. Hydrolyzed casein reduces browsing of trees and shrubs by white-tailed deer. Hortscience 2005;40:1810-4.
[25] Kimball BA, Nolte DL. Development of a new deer repellent for the protection of forest resources. West J Appl For 2006;21:108-11.

[26] Jacobs WW. Taste responses in wild and domestic guinea pigs. Physiol Behav 1978;20:579-88.

[27] Glendinning JI. Is the bitter rejection response always adaptive. Physiol Behav 1994;56:1217-27.

[28] Nolte DL, Mason JR, Lewis SL. Tolerance of bitter compounds by an herbivore, Cavia porcellus. J Chem Ecol 1994;20:303-8.

[29] Beauchamp GK, Maller O, John G, Rogers J. Flavor preferences in cats (Felis catus and Panthera sp). J Comp Physiol Psychol 1977;91:1118-27.

[30] Ribeiro RPP, DeOliveira LM, DosSantos JE. Selection of an intact casein or casein hydrolysate diet by rats submitted to protein deprivation and bowel resection. Physiol Behav 1998;63:185-9.

[31] Bachmanov AA, Tordoff MG, Beauchamp GK. Intake of umami-tasting solutions by mice: a genetic analysis. J Nutr 2000;130:935S-41S.

[32] Bachmanov AA, Reed DR, Tordoff MG, Price RA, Beauchamp GK. Intake of ethanol, sodium chloride, sucrose, citric acid, and quinine hydrochloride solutions by mice: a genetic analysis. Behav Genet 1996;26:563-573.

[33] McArthur RA, Blundell JE. Dietary self-selection and intake of protein and energy is altered by the form of the diets. Physiol Behav 1986;38:315-9.

[34] Ramirez I. Influence of experience on response to bitter taste. Physiol Behav 1991;49:387-91.

[35] Sorensen LB, Moller P, Flint A, Martens M, Raben A. Effect of sensory perception of foods on appetite and food intake: a review of studies on humans. Int J Obes Relat Metab Disord 2003;27:1152-66.

[36] Baumont R. Palatability and feeding behaviour in ruminants. A review. Ann Zootech 1996;45:385-400.

[37] Bertino M, Beauchamp GK. The spontaneously hypertensive rat's preference for salted foods. Physiol behav 1988;44:285-9.

[38] Welch CC, Grace MK, Billington CJ, Levine AS. Preference and diet type affect macronutrient selection after morphine, npy, norepinephrine, and deprivation. Am J Physiol, Regul Integr comp physiol 1994;266:R426-33.

[39] Smith BK, Berthoud HR, York DA, Bray GA. Differential effects of baseline macronutrient preferences on macronutrient selection after galanin, NPY, and an overnight fast. Peptides 1997;18:207-11.

[40] Blundell JE. Problems and processes underlying the control of food selection and nutrient intake. In: Wurtman RJ, Wurtman JJ, editors. Nutrition and the brain. New York: Raven Press; 1983. p. 163-221.

[41] Reeves PG. Ain-93 purified diets for the study of trace element metabolism in rodents. In: Watson RR, editor. Trace elements in laboratory rodents. Boca Raton, FL: CRC Press; 1996. p. 3-37.

[42] Sokal RR, Rohlf FJ. Biometry: the principles and practice of statistics in biological research. 3rd ed. New York: W.H. Freeman and Company; 1995. p. 239.

[43] Woods SC. The eating paradox: how we tolerate food. Psychol Rev 1991;98:488-505.

[44] Raynor HA, Epstein LH. Dietary variety, energy regulation, and obesity. Psychol Bull 2001;127:325-41.

[45] Scott EM. Self selection of diet. 1. Selection of purified components. J Nutr 1946;31:397-406.

[46] Smith BK, Andrews PK, West DB. Macronutrient diet selection in thirteen mouse strains. Am J Physiol, Regul Integr Comp Physiol 2000;278: R797-805.

[47] Sanders S, Ackroff K, Collier GH, Squibb R. Purified diets some cautions about casein. Physiol Behav 1984;33:457-64.

[48] Alexander J, Chang GQ, Dourmashkin JT, Leibowitz SF. Distinct phenotypes of obesity-prone AKR/J, DBA2J, and C57BL/6J mice compared to control strains. Int J Obes (Lond) 2006;30:50-9.

[49] Mihatsch WA, Franz AR, Kuhnt B, Hogel J, Pohlandt F. Hydrolysis of casein accelerates gastrointestinal transit via reduction of opioid receptor agonists released from casein in rats. Biol Neonate 2005;87:160-3.

[50] Calbet JAL, Holst JJ. Gastric emptying, gastric secretion and enterogastrone response after administration of milk proteins or their peptide hydrolysates in humans. Eu J Nutr 2004;43:127-39.

[51] Moughan PJ, Pedraza M, Smith WC, Williams M, Wilson MN. An evaluation with piglets of bovine milk hydrolyzed bovine milk and isolated soybean proteins included in infant milk formulas. I. Effect on organ 
development, digestive enzyme activities, and amino acid digestibility. J Pediatr Gastroenterol Nutr 1990;10:385-94.

[52] Moughan PJ, Cranwell PD, Smith WC. An evaluation with piglets of bovine milk, hydrolyzed bovine milk, and isolated soybean proteins included in infant milk formulas. 2. Stomach-emptying rate and the postprandial change in gastric ph and milk-clotting enzyme activity. J Pediatr Gastroenterol Nutr 1991;12:253-9.

[53] Coutinho EM, Ferreira HS, Assunção ML, Carvalho SL, Oliveira SA, Francelino AA. The use of protein hydrolysate improves the protein intestinal absorption in undernourished mice infected with Schistosoma mansoni. Rev Soc Bras Med Trop 2002;35:585-90.

[54] L'Heureux-Bouron D, Tome D, Bensaid A, Morens C, Gaudichon C, Fromentin G. A very high 70\%-protein diet does not induce conditioned taste aversion in rats. J Nutr 2004;134:1512-5.

[55] L'Heureux-Bouron D, Tome D, Bensaid A, Morens C, Lacroix M, Huneau JF, Fromentin G. Preabsorptive factors are not the main determinants of intake depression induced by a high-protein diet in the rat. Physiol Behav 2004;81:499-504. 